\title{
Liquid-Chromatographic Determination of Indole-3-acetic Acid and 5-Hydroxyindole-3-acetic Acid in Human Plasma
}

\author{
E. Martínez, F. Artigas, C. Suñol, J. M. Tusell, and E. Gelpí
}

We describe a "high-performance" reversed-phase liquidchromatographic method for determination of indole-3-acetic acid (I) and 5-hydroxyindole-3-acetic acid (II) in human plasma. I is eluted at $1.0 \mathrm{~mL} / \mathrm{min}$ with a mixture of 1 pentanesulfonic acid ( $\mathrm{pH} \mathrm{3.1),} \mathrm{methanol,} \mathrm{and} \mathrm{water.} \mathrm{It} \mathrm{is}$ detected by fluorometry. A mixture of citric acid/sodium phosphate solution (pH 4.8) and methanol, at $1.5 \mathrm{~mL} / \mathrm{min}$, is used to elute II, which is detected with an electrochemical cell. Platelet-poor plasma samples were pretreated with $\mathrm{HCl}$, perchloric acid, and trichloroacetic acid for protein precipitation. Best results were obtained with the last (protein precipitation is incomplete with $\mathrm{HCl}$, while recoveries of $\mathbf{I}$ are concentration dependent with perchloric acid). Analytical recoveries were $58 \%$ (SD $3.1 \%$, CV $5.3 \%, n=12$ ) and $79 \%$ (SD $3.3 \%$, CV $5.3 \%, n=9$ ) for I and II, respectively. Concentrations of I and II in plasma ranged from 0.61 to 3.32 (mean 1.54, SD 0.59, $\mathrm{n}=15$ ) $\mu \mathrm{mol} / \mathrm{L}$ and from 33.0 to 102.6 (mean 51.8, SD 20.1, $n=16$ ) $\mathrm{nmol} / \mathrm{L}$, respectively.

Additional Koyphrases: reference value - fluorometry - electrochemical detection - neurological and psychiatric disorders - bio-amines

The metabolism of 5-hydroxytryptamine has been implicated in the etiology of psychiatric disorders such as depressive states (1) as well as in other neurological alterations (for a review, see 2). Also, alterations of 5-hydroxytryptamine metabolism have been described in the carcinoid syndrome (3) as well in several types of cancer (4). 5Hydroxytryptamine, which is derived from tryptophan through ring hydroxylation (tryptophan hydroxylase, EC 1.14.16.4) and subsequent decarboxylation of 5-hydroxytryptophan (aromatic L-aminoacid decarboxylase, EC 4.1.1.28) is mainly metabolized by deamination (monoamine oxidase, EC 1.41.3.4), yielding 5-hydroxyindole-3-acetic acid (5HIAA). ${ }^{1}$ Measurements of the concentration of this catabolite in the cerebrospinal fluid have been used as an index of serotonergic activity in the central nervous system (5) or, measured in urine, as an index of total 5-hydroxytryptamine activity (6).

The behaviorally-active trace amine, tryptamine, is produced in mammals through decarboxylation of tryptophan, a common precursor of both amines. At present, several lines of evidence suggest a possible neuromodulator activity of tryptamine in the central nervous system (7-9). However, to date, no clear implications of the metabolism of this amine in psychiatric disorders have been proven, even though several classic treatments of depressive states (tryptophan loading, monoamine oxidase inhibitor administra-

Analytical Neurochemistry Unit, Instituto de Química Bio-Orgánica. C.S.I.C., c/ Jorge Girona Salgado, s/n. Barcelona-34, Spain.

1 Nonstandard abbreviations: 5HIAA, 5-hydroxyindole-3-acetic acid; HPLC, "high-performance" liquid chromatography; IAA, indole-3-acetic acid; PCA, perchloric acid; PPP, platelet-poor plasma; and TCA, trichloroacetic acid.

Received Nov. 9, 1982; accepted Mar. 22, 1983. tion) have been shown to increase the concentration of tryptamine in the brain dramatically (10). Also, because it readily crosses the blood-brain barrier (11), peripheral metabolism of this amine can influence its availability in brain. Tryptamine is also deaminated by monoamine oxidase, yielding indole-3-acetic acid (IAA). The ratio between IAA and tryptamine, measured in urine, has been used as an index of monoamine oxidase activity in humans (12).

Thus, the concentrations of either 5HIAA and IAA, or both, can be taken as an index of the functional activity of the indoleaminergic pathways of tryptophan, and consequently both acids have been measured in cerebrospinal fluid $(5,13)$ and urine $(6,14)$. However, to our knowledge, there are no published values for either of these compounds in normal human plasma.

As a part of a more-complex study concerning the concentrations of tryptophan, tryptamine, serotonin, IAA, and 5HIAA in platelets and platelet-poor-plasma (PPP) samples from healthy individuals and depressive patients, we present here a liquid-chromatographic assay of 5HIAA and IAA in plasma samples from healthy volunteers.

Both compounds were chromatographed on a reversedphase column. The low concentration of 5HIAA in plasma samples required use of an electrochemical detector. IAA was monitored fluorometrically, capitalizing on the relatively strong natural fluorescence of indolic compounds.

Several gas-chromatographic/mass-spectrometric techniques are available for use in analysis for both compounds in cerebrospinal fluid and brain tissue $(5,13,15-17)$ but we consider "high-performance" liquid chromatography (HPLC) coupled to specific detectors such as the electrochemical or fluorometric detectors to be the analytical technique of choice because there is less sample handling, easier automation, and faster analysis.

\section{Materials and Methods}

\section{Reagents}

All chemicals were of analytical grade. Methanol used as chromatographic eluent was "HPLC" grade.

\section{Standards}

Stock $1.0 \mathrm{~g} / \mathrm{L}$ solutions of 5HIAA and IAA (Sigma Chemical Co., St. Louis, MO 63178) were prepared weekly in isotonic saline and stored at $4{ }^{\circ} \mathrm{C}$. Working standards were freshly prepared by diluting stock solutions.

Qualitative stock solutions of tryptophan, tryptamine, 5hydroxytryptamine, 4-hydroxy-3-methoxymandelic acid, dopamine, 3,4-dihydroxyphenylacetic acid, 4-hydroxy-3 methoxy phenylethyleneglycol, 4-hydroxy-3-methoxy phenylacetic acid, indole-3-pyruvic acid, and indole-3-propionic acid were prepared, with the chromatographic eluent system as the solvent.

\section{Apparatus}

We used a M6000 solvent-delivery system with an automatic sample injector (WISP 710B; Waters Associates Inc., 
Milford, MA 01757), a Model 650-10S fluorescence detector (Perkin-Elmer Corp., Norwalk, CT 06856) or a Model LC-4A amperometric detector (Bioanalytical Systems Inc., West Lafayette, IN 47906), and a Model 56 (Perkin-Elmer) recorder.

The chromatographic column was $30 \mathrm{~cm}$ long, $3.9 \mathrm{~mm}$ i.d., filled with $\mu$ Bondapack $\mathrm{C}_{18}$ reversed phase (Waters Assoc.). A guard column ( $\mu$ Bondapack $\mathrm{C}_{18}$, also from Waters Assoc.) was attached btween the injector and the chromatographic column.

For chromatographic analysis with fluorometric detection we used a mobile phase consisting of an equivolume mixture of 1-pentanesulfonic acid (PIC B-5, Waters Assoc.) $5 \mathrm{mmol} /$ $\mathrm{L}, \mathrm{pH} 3.1$, and methanol/water (7/3 by vol), at a flow rate of $1.0 \mathrm{~mL} / \mathrm{min}$. Excitation and emission wavelengths were set at $280 \mathrm{~nm}$ and $340 \mathrm{~nm}$, respectively.

When the electrochemical detector was used, the mobile phase consisted of a $94 / 6$ (by vol) mixture (pH 4.8) of citric acid $30 \mathrm{mmol} / \mathrm{L})$, disodium hydrogen phosphate $(60 \mathrm{mmol} / \mathrm{L})$ and methanol, at a flow rate of $1.5 \mathrm{~mL} / \mathrm{min}$. The potential of the glassy carbon electrode was set to $0.55 \mathrm{~V}$ vs the $\mathrm{Ag} / \mathrm{AgCl}$ reference electrode.

\section{Plasma Samples}

Blood was sampled from ostensibly healthy adult volunteers who had fasted overnight. Samples were drawn by venipuncture at 0900 hours into polypropylene tubes containing EDTA in saline $(5.0 \mathrm{~g} / \mathrm{L}$; one vol per three vol of blood). The contents of the tubes were gently mixed by several inversions. PPP samples were obtained by centrifuging the whole blood $\left(1000 \times \mathrm{g}, 10 \mathrm{~min}, 4^{\circ} \mathrm{C}\right)$. The supernates were carefuly removed and stored at $-40^{\circ} \mathrm{C}$ until analyzed.

For methodological studies we used a single specimen of plasma, corresponding to $100 \mathrm{~mL}$ of blood from one donor. Observed values were derived by use of 3-mL specimens from each of 16 different healthy individuals.

\section{Procedure}

To $0.2 \mathrm{~mL}$ of PPP in a polypropylene tube, add $40 \mu \mathrm{L}$ of a $20 \mathrm{~g} / \mathrm{L}$ ascorbic acid solution and either $25 \mu \mathrm{L}$ of cold concentrated perchloric acid (PCA) or $300 \mu \mathrm{L}$ of a $50 \mathrm{~g} / \mathrm{L}$ solution of trichloroacetic acid (TCA). Shake the mixture vigorously, allow it to stand for $5 \mathrm{~min}$, then centrifuge (2000 $\times g, 15 \mathrm{~min}$ ). When PCA is used, adjust the $\mathrm{pH}$ of the clear supernate to $1.5-2$ with a $10 \mathrm{~mol} / \mathrm{L}$ solution of $\mathrm{NaOH}$. Do all of the above at $4^{\circ} \mathrm{C}$.

Inject aliquots of the supernate directly into the liquid chromatograph. Run the chromatographic analyses at room temperature.

\section{Quantification}

PPP samples were supplemented with the appropriate amounts of IAA or 5HIAA (see results) and subjected to the procedure described above. The endogenous 5HIAA or IAA in plasma was calculated in each sample by comparing peak heights of the corresponding "endogenous" and "supplemented" aliquots.

\section{Results}

Both acid metabolites, IAA and 5HIAA, were chromatographed on the same reversed-phase column, as described in the previous section. However, the choice of the most suitable detector system was based in each case on the sensitivity of response needed to work within the physiological working range. For instance, a few picograms of 5HIAA can readily be detected by an electrochemical cell operated at $0.5-0.7 \mathrm{~V}(18,19)$. In contrast, detection of IAA would require a relatively higher electrochemical detector electrode potential, which in turn would generate a high interfering background signal, because of the oxidation of many other components of the samples, thus masking the response of endogenous IAA. Consequently, this strongly fluorescent acid is best monitored fluorometrically. Figure $1(A$ and $B)$ shows the chromatographic profiles of both acids in plasma. Detection limits for both compounds have been reported elsewhere $(19,20)$. We recently reported a liquid-chromatographic procedure for determining 5HIAA, with electrochemical detection, in brain tissue (19); the procedure for IAA is a modification of another method, also recently reported (20). The advantage of the latter is that because it is an isocratic elution procedure, as for the 5HIAA determination, it facilitates the use of an automatic injector, which is convenient in routine work.

The excellent performance of these chromatographic procedures, not only in terms of sensitivity but also of specificity-both peaks are free from coeluting interferences (Table 1)-and reproducibility of retention time (Table 1), make them particularly suitable for the kind of determinations we report here. Furthermore, the conspicuous absence of published reference or observed values is the natural consequence of the lack hitherto of simple, reliable analytical methods for assay of these compounds. Thus, after we developed an adequate HPLC procedure with standards, we

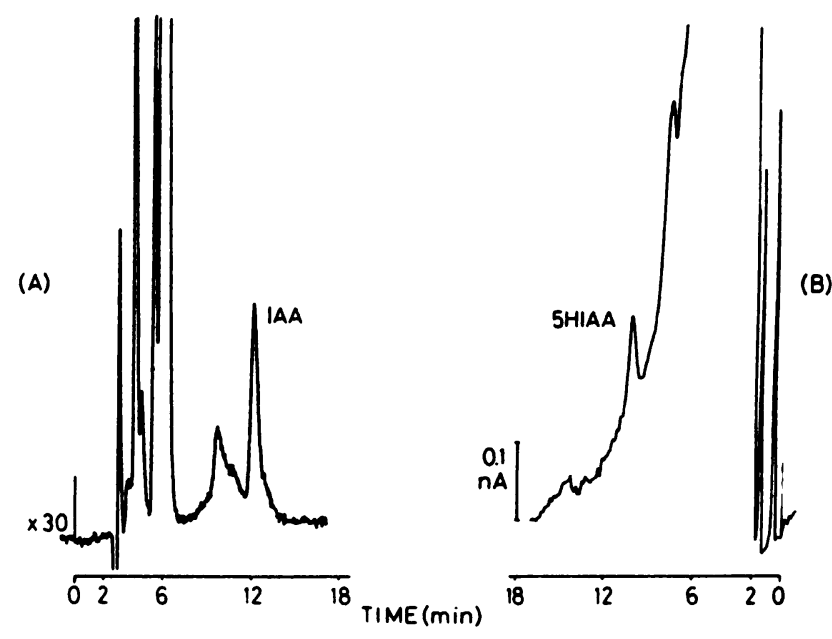

Fig. 1. HPLC profiles of IAA and 5HIAA from plasma samples $A$, fluorometric response with the 1-pentanesulfonic acid/methanol eluent system. $B$, amperometric response with the citrate/phospate/methanol eluent system

Table 1. Relative Retention Volumes of Some Indole- and Catechol-Related Compounds

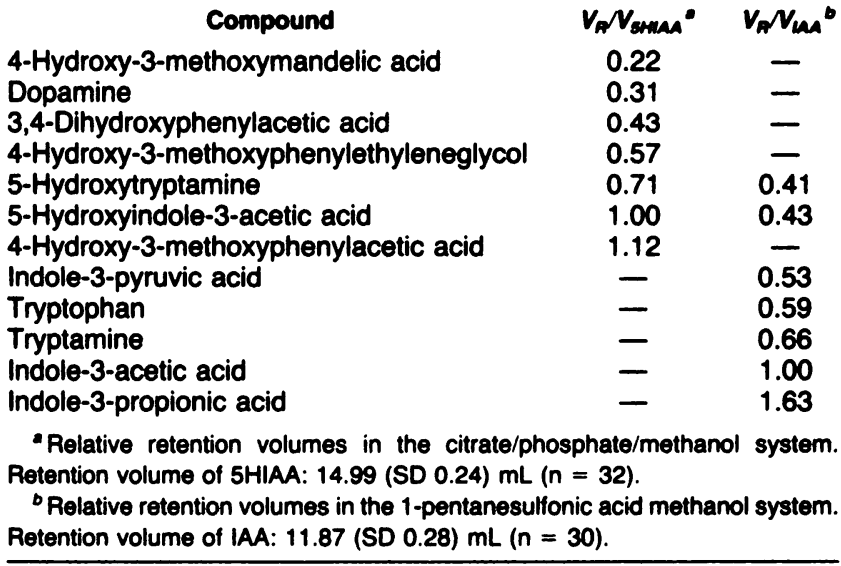


next assessed the pretreatment steps necessary to render blood samples suitable for direct chromatographic assay, optimizing recoveries and sample stabilities.

For the sake of simplicity and speed, our first attempts involved addition of $1 \mathrm{~mol} / \mathrm{L} \mathrm{HCl}$ to the plasma samples, to adjust their $\mathrm{pH}$ to 2.0 before injecting them into the liquid chromatograph, a convenient way to stabilize indoles $(6,21)$. However, $\mathrm{HCl}$ was unsatisfactory, especially for a mobile phase containing $50 \%$ methanol; column filters become clogged with protein, column pressure increases, and resolution becomes poor. In fact, after no more than 10 injections, chromatographic performance was appreciably degraded. The $\mathrm{HCl}$ procedure would contribute to preventing losses of IAA through its possible occlusion by the precipitating proteins, thus facilitating the quantitative assay by external calibration, but it would not be useful in practice for the above reasons. The mean value obtained in this way for five determinations of the plasma sample used for calibration of the method was 1.25 (SD 0.04) $\mu \mathrm{mol} / \mathrm{L}$.

To obviate this problem, we removed plasma proteins by precipitation with either PCA or TCA. The advantages of either one of these deproteinizing agents in the assay of IAA in human plasma were evaluated as follows. Twelve $200-\mu \mathrm{L}$ samples of donor's PPP were each supplemented.with increasing amounts of authentic IAA (final concentration of added IAA: 0.38 to $3.77 \mu \mathrm{mol} / \mathrm{L}$ ), thus obtaining four groups of three samples each. These were assayed by HPLC after protein precipitation with either PCA or TCA. For plasma samples treated with PCA, the CV of each of the replicate data points was $3.2 \%$. The points lay along a straight line defined by the intercept and slope included in Figure $2 A$. The corresponding correlation coefficient was $r^{2}=.9990$ and the experimentally measured endogenous IAA peak height was 66.6 units, in agreement with the calculated value of 65.4 (see intercepts in Figure 2A). Figure $2 A$ also shows the regression line corresponding to IAA standard solutions treated as plasma samples, and run in duplicate. The calculated average recovery for the four different concentrations of IAA ( $\mathrm{n}=12$ ) was 25.8 (SD 5.7), the CV $22 \%$. However, recovery was found to depend on the concentration of IAA. It increased in parallel with the amount added,

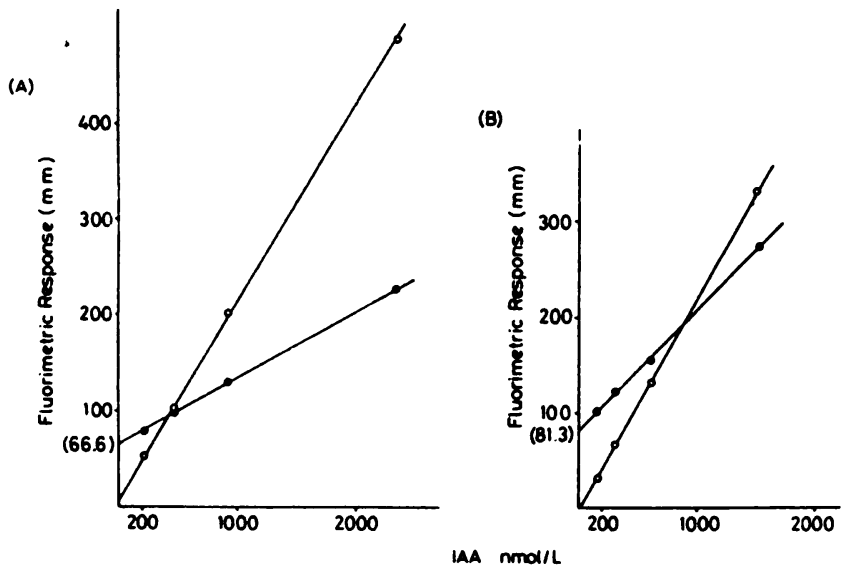

Fig. 2. Response of IAA standards (O) and IAA-supplemented PPP (O) after deproteinization treatment with $(A)$ PCA and $(B)$ TCA

A. The adjusted straight line $(y=a+b x)$ parameters for standards and PPP were respectively $\mathrm{a}=7.104, \mathrm{~b}=0.209, r^{2}=0.9999$, and $\mathrm{a}=65.440, \mathrm{~b}=0.069$, $r^{2}=0.9990$. B. The corresponding parameters in TCA treatment were $a=$ $-0.188, b=0.2208, r^{2}=0.9993$, and $a=81.494, b=0.125, r^{2}=0.9997$. Abcissa: concentration of IAA in the standards and the concentration of exogenous IAA added to the PPP. Ordinate: the fluorometric response, in millimeters on the recorder paper, corresponding to $50 \mu \mathrm{L}$ of injected sample. The figures shown in parentheses correspond to the experimental value obtained for unsupplemented PPP.
Table 2. Analytical Recoveries and Quantitation of IAA in Platelet-Poor Plasma Treated with Trichloroacetic acid

IAA, $\mu \mathrm{mol} / \mathrm{L}$

\begin{tabular}{|c|c|c|}
\hline \multicolumn{2}{|c|}{ IAA, $\mu \mathrm{mo} \mid \mathrm{L}$} & \multirow[t]{2}{*}{ Recovery, \% } \\
\hline Conen added & Endogenous conen & \\
\hline $\begin{array}{l}0.38 \\
0.75 \\
1.51 \\
3.77\end{array}$ & $\begin{array}{c}1.46 \\
1.63 \\
1.60 \\
1.58 \\
\text { mean } 1.57(\text { SD } 0.07)^{a}\end{array}$ & $\begin{array}{c}62.6 \\
56.0 \\
56.4 \\
57.0 \\
\text { mean } 58.0 \text { (SD 3.1) }\end{array}$ \\
\hline
\end{tabular}

- This concentration of IAA in PPP would be equivalent to a concentration of $2.09 \mu \mathrm{mol} / \mathrm{L}$ in human plasma.

which effectively invalidates the method for practical purposes.

On the other hand, plasma samples treated with TCA gave a straight line, the CV being $2.3 \%$ for each of the triplicate measurements. In this case, the regression equation is as shown in Figure 2B. The measured IAA peak height in the chromatogram of the unsupplemented sample was 81.3. Similarly, standard solutions of increasing concentrations of IAA, each treated with TCA as with actual plasma samples, gave a straight line (Figure $2 B$ ) intersecting the $x$-axis at $65 \mathrm{fmol}$ of IAA, equivalent to $11.4 \mathrm{pg}$. The mean recovery improved in this case to $58 \%$ with $\mathrm{SD}=3.1$ and $\mathrm{CV}=5.3 \%$ for $\mathrm{n}=12$ and, in contrast to the variation observed when PCA was used, the recovery values for different IAA concentrations in plasma are similar within the working range $0.38-3.77 \mu \mathrm{mol} / \mathrm{L}$ (Table 2).

Our results nevertheless prove that there are no degradative losses with either TCA or PCA, as shown by the regression data corresponding to the standard solutions. Furthermore, washing the PCA or TCA protein precipitate does not increase recoveries by more than $15 \%$ at most, whereas the additional dilution decreases the concentration of the acids in the samples, thus diminishing sensitivity.

5HIAA (Figure $1 B$ ) was assayed in the same way, with recoveries in this case of $78.8 \%$ (SD $3.3 \%$ and CV $4.2 \%$ ). Figure 3 shows the calibration plot for the determination of endogenous values of this acid in human plasma treated with TCA.

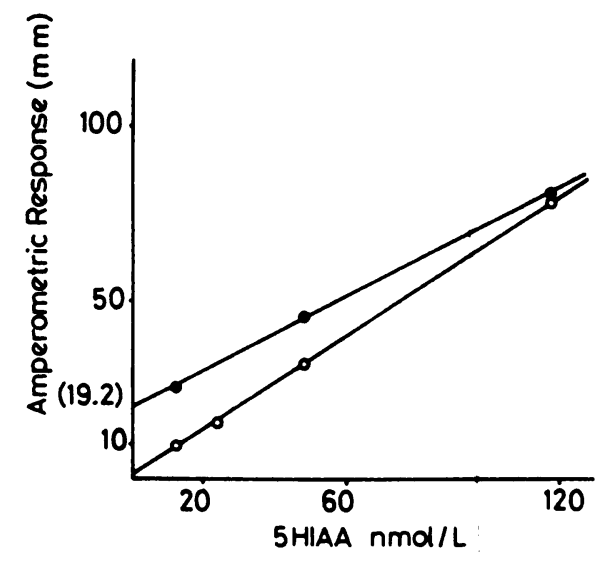

Fig. 3. Response of 5HIAA standards $(O)$ and 5HIAA-supplemented PPP $(O)$ after treatment with TCA

The adjusted straight-line parameters for standards and PPP were respectively a $=1.260, \mathrm{~b}=0.6537, r^{2}=0.9997$, and $\mathrm{a}=20.513, \mathrm{~b}=0.519, r^{2}=0.9996$. Abcissa: the concentration of 5HIAA for the standards and the concentration of the exogenous 5HIAA added to the PPP. Ordinate: the amperometric response, in millimeters on the recorder paper, corresponding to $80 \mu \mathrm{L}$ of injected samples. The figure shown in parentheses corresponds to the experimental value obtained for unsupplemented PPP 


\section{Table 3. Mean Values for IAA and 5HIAA in Human Plasma}

IAA

$\begin{array}{ll}n=15 \text { (13 men, } 2 \text { women) } & n=16 \text { (14 men, } 2 \text { women) } \\ \bar{X}=1.54 \mu \mathrm{mol} / \mathrm{L} & \bar{X}=51.8 \mathrm{nmol} / \mathrm{L} \\ \mathrm{SD}=0.59 \mu \mathrm{mol} / \mathrm{L} & \mathrm{SD}=20.1 \mathrm{nmol} / \mathrm{L} \\ \text { Range } 0.61-3.32 \mu \mathrm{mol} / \mathrm{L} & \text { Range } 33.0-102.6 \mathrm{nmol} / \mathrm{L} \\ \text { Mean donor age } 29 \mathrm{yr} \text { (SD 4.9; range 24-39). }\end{array}$

The values observed for both acids are given in Table 3. Interferences due to other related compounds also present in plasma samples are ruled out by their significantly different retention volumes (Table 1). Furthermore, the reproducibility of the retention data is excellent, as shown also in this table for both acids, contributing further to the reliability of the method.

A significant correlation ( $p<.05, \mathrm{n}=16$ ) was found between body weight and the concentration of 5HIAA in plasma.

The observed values for both acids differ by a factor of 30 , IAA being greater than 5HIAA. This is interesting, because IAA is the principal metabolite of tryptamine, and no clear physiological or pathological roles have yet been found for it.

Work is in progress to determine the significance of this relatively high IAA concentration in human plasma for healthy volunteers.

We thank all members of this Institute who volunteered to donate blood. This work was supported by a research grant from the Comisión Asesora de Investigación Cientifica y Técnica (3300/79) and by a research grant from the Consejo Superior de Investigaciones Cientificas.

\section{References}

1. Van Praag HM. Management of depression with serotonin precursors. Biol Psychiatr 16, 291-309 (1981).

2. Serotonin in Mental Abnormalities. DJ Boullin, Ed., John Wiley \& Sons, Chichester, U.K., 1978.

3. Gowenlock AH, Platt DS. The clinical chemistry of carcinoid tumours. In The Clinical Chemistry of Monoamines 2, H Varley, AH Gowenlock, Eds, Elsevier, Amsterdam, 1963, pp 140-164.

4. Horai T, Nishihara H, Hattori S, Tateishi R. Malignant melanoma producing serotonin. Cancer 43, 294-298 (1979).

5. Bertilsson L, Atkinson AJ, Althaus JR, et al. Quantitative determination of 5HIAA in cerebrospinal fluid by GC-MS. Anal Chem 44, 1434-1438 (1972).
6. Fornstedt N. Determination of 5HIAA in urine by high performance liquid chromatography. Anal Chem 50, 1342-1346 (1978).

7. Jones RSG, Boulton AA. Tryptamine and 5-hydroxytryptamine: Actions and interactions on cortical neurones in the rat. Life Sci 27 , 1849-1856 (1980).

8. Cox B, Lee TE, Martin D. Different hypothalamic receptors mediate $5 \mathrm{HT}$ and T-induced core temperature changes in the rat. $\mathrm{Br}$ $J$ Pharmacol 72, 477-482 (1981).

9. Marsden CA, Curzon G. The role of tryptamine in the behavioural effects of tranylcypromine + L-tryptophan. Neuropharmacology 18, 159-164 (1979).

10. Philips SR, Boulton AA. The effect of monoamine oxidase inhibitors on some arylalkylamines in rat striatum. $J$ Neurochem 33, 159-167 (1979).

11. Oldendorf WH, Braun LD. ${ }^{3} \mathrm{H}$-Tryptamine and ${ }^{3} \mathrm{H}$-water as diffusible internal standards for measuring brain extraction of radiolabeled substances following carotid injection. Brain Res 113, 219-224 (1976).

12. Stachow A, Bousquet B, Dreux C. Variation du rapport trypamine/acide indolylacetique urinaire dans divers cas pathologiques affectant le metabolisme du tryptophanne. Clin Chim Acta 50, 329 335 (1974).

13. Bertilsson L, Palmer L. Indole-3-acetic acid in human cerebrospinal fluid: Identification and quantification by mass fragmentography. Science 177, 74-76 (1972).

14. Anderson GM, Purdy WC. Liquid chromatographic-fluorimetric system for the determination of indoles in physiological samples. Anal Chem 51, 283-286 (1979).

15. Artigas F, Gelpí E. A new mass fragmentographic method for the simultaneous analysis of tryptophan, tryptamine, indole-3acetic acid, serotonin and 5-hydroxyindole-3-acetic acid in the same sample of rat brain. Anal Biochem 92, 233-242 (1979).

16. Beck $O$, Wiesel FA, Sedvall G. Mass fragmentographic determination of 5-hydroxytryptamine and 5-hydroxyindoleacetic acid in brain tissue using deuterated internal standards. J Chromatogr 134, 407-414 (1977).

17. Warsh JJ, Chan PW, Godse DD, et al. Gas chromatographymass fragmentographic determination of indole-3-acetic acid in rat brain. J Neurochem 29, 955-958 (1977).

18. Koch DD, Kissinger PT. Determination of tryptophan and several of its metabolites in physiological samples by reversedphase liquid chromatography with electrochemical detection. $J$ Chromatogr (Biomed Appl) 164, 441-455 (1979).

19. Tusell JM, Suñol C, Artigas F, et al. Neurochemical studies on catecholamines and indoleamines by HPLC with electrochemical detection. Chromatographia 16, 112-116 (1982).

20. Adell A, Tusell JM, Artigas F, et al. Fluorometric determination of tryptophan and its brain indoleamine metabolites by ionpair HPLC. $J$ Liq Chromatogr (in press).

21. Geeraerts F, Schimpfessel L, Crokaert R. The stability of tryptophan metabolites prior to urine analysis. Clin Chim Acta 102, 247-251 (1980). 